\title{
A Bridging Approach to Boost Doctoral Enrollment in a HBCU: An Exploratory Qualitative Study
}

\author{
Charles M. S. Birore ${ }^{1} \&$ Liyun $\mathrm{Wu}^{1}$ \\ ${ }^{1}$ School of Social Work, Norfolk State University, Norfolk, USA \\ Correspondence: Liyun Wu, School of Social Work, Norfolk State University, 700 Park Avenue, Norfolk, 23504, \\ Virginia. Tel: 1-757-823-9037. E-mail: 1wu@nsu.edu
}

Received: October 27, 2017

Accepted: November 2, 2017 Online Published: November 10, 2017

doi:10.5539/hes.v7n4p88

URL: http://doi.org/10.5539/hes.v7n4p88

\begin{abstract}
A declining enrollment in doctoral social work programs not only affects the sustainability of the programs, but also impacts the knowledge-based economy in the long run. The shortage of doctoral-prepared faculty, interwoven with the current national shortage of social workers, will limit effective service delivery, and generation of knowledge base for direct practice and policy advocates. Little is known about the barriers and strategies in Historically Black Colleges and Universities (HBCU). Two focus groups with in-depth interviews were conducted among Master of Social Work (MSW) students at a four-year public university. The study resulted in a wide range of identifiable strategies to boost the doctoral enrollment in the social work program, including more summer courses, more online courses, more flexible class time, higher integration of technology in the classroom and better curriculum structure. Findings suggest that non-traditional becomes the new traditional. With the advancement in smartphone and wireless technology, the University can reposition the program, seek for ways to serve the new traditional student population, and improve the infrastructure to accommodate students' digital needs.
\end{abstract}

Keywords: social work, enrollment, non-traditional, HBCU

\section{Introduction}

\subsection{Introduce the Problem}

Increasing undergraduate and graduate students' enrollment is the hallmark of colleges' and universities' survival in contemporary America, especially in Historically Black Colleges and Universities (HBCUs). Thus, recruitment and enrollment in the doctoral degree programs are critical issues facing social work graduate programs in general. Studies indicate a disproportionate number of qualified educators with a doctoral degree in social work relative to the number of applicants enrolling and attaining doctoral degrees in this discipline (Anastas, 2012; Council on Social Work Education (CSWE), 2014, 2010; Kirk, Corcoran, \& Kil, 2009; Whitaker, Weismiller, \& Clark, 2006; Zastrow \& Bremner, 2004). The declining enrollment in doctoral programs in particular is a great concern for the continuity of the social work education and profession. It is worse for HBCUs, which historically are underfunded and continue to be underfunded. Despite growth of social work doctoral programs in the country (47.9\%) from the years 1990 (48) to 2014 (71), shortage of social work educators with a doctoral degree threatens the success of the growing number of undergraduate and graduate programs in social work.

The general purpose of doctoral education is to train stewards of the discipline, who are dedicated to generating, conserving, and transforming knowledge (Golde \& Walker, 2006; Golde, Jones, Bueschel, \& Hutchings, 2008). With regard to that purpose, doctoral education in social work prepares students to become scholars who function as scholars to improve the art and science of social work by generating, disseminating, and conserving the knowledge that informs and transforms professional practice (Advancement of Doctoral Education in Social Work (GADE), 2013). A steward of the discipline, according to the Carnegie Initiative on the doctoral education is one who generates and critically evaluates new knowledge, conserves the most important ideas and findings that are the legacy of the discipline, understands how knowledge is transforming the discipline and the larger world, and communicates his/her knowledge responsibly to others (Walker et al., 2008). 
Kirk et al. (2009) examined CSWE data to determine how selectively social wok schools admitted full-time M.S.W. and Ph.D. students during 1990 through 2004. Overall, they found a great variation in selection of applicants to doctoral programs, with an admittance rate of $21 \%$ to $82 \%$ of the applicants. The number of applicants to the doctoral program increased from 1,100 in 1990 to 1,500 in 2004. Surprisingly, the number of students accepted into those programs (620 to 680) and the number enrolled (450) remained unchanged even though the number of doctoral programs increased from 48 to 66 during the same period. Kirk and colleagues also found that a small number of social work doctoral programs attracted more qualified applicants annually than they could admit, while other programs sought additional applicants and some admitted a very small number of doctoral students at a time. Additionally, they found that at the aggregate national level there was an increase in the number of full-time students admitted and enrolled in MSW programs since 2002. There were fewer full-time students per program in 2004 compared to almost all 15 years after 1990. The increases in the number of admitted and enrolled full-time MSW students (potential doctoral applicants) did not keep pace with the growth in the number of accredited MSW programs during the same period. There was a decline of $13 \%$ from 1990 (129) to 2004 (112) in the average number of full-time MSW students admitted per school.

\subsection{Explanations for Declining Enrollment}

Whitaker et al. (2006) identified an impending shortage of social workers due to several factors. These factors include the need to replace retiring workers due to the age of the workforce, difficulties retaining the current workforce due to workplace and service delivery challenges, concerns about recruiting the next generation of social workers due to high levels of student loan debt, and low salaries for social work positions.

Explanations for declining enrollment in doctoral social work programs may be associated with lack of or inadequate financial aid over years due to economic hardships and tight state and federal budgets (Anastas, 2012). Three major economic forces that impact enrollment and retention of students in colleges and universities are evident. The first force is the soaring costs of higher education including tight budgets for operational costs such as administration and maintenance of physical facilities and faculty and staff salaries (College Board, 2009). In order to offset the operational costs, it is imperative that deliberate efforts are made to rapidly increase and sustain enrollment. The second is allocation of funds for better performing institutions of higher education. There is an increased demand for optimal performance of these institutions on key outcome indicators such as student retention and graduation rates in a timely manner and equal access to higher education as a right for every citizen (AASCU, 2002; Harnisch, 2011; Watson, 2010). The third economic force is increased reliance on tuition and fees as revenue for running the university, especially HBCUs that admit a large number of students from low-income families.

However, the declining problem is more than just financial support. It may include lack of motivation to apply to doctoral social work programs, low level of perceived value of the utility of doctoral degree, reduced satisfaction with the program, stress, and ambivalence of committing to the process and devoting time to completion. With regard to the process and length of time to completion of the program, potential applicants may fear that once enrolled, rigorous research-based academic activities, duration to completion, and stress attached to it all may endanger the quality of their relationships with their partners and other family members. Additionally, low salaries for faculty with doctoral degree may deter potential applicants to the doctoral program. Although little is known about factors influencing the declining enrollment to doctoral degree in social work across the country, studies to date that have exclusively examined the impact of these factors on this issue are either limited or non-existent.

Another contributing factor may relate to a tedious and expensive process of hiring faculty with doctorates to teach in graduate and undergraduate programs. The processes may discourage potential enrollees in doctoral programs and send a negative message. Currently the CSWE (2012) requires social work educators in universities and colleges to have work experiences and hold both masters and doctoral degrees in social work from accredited institutions in order to teach graduate courses. Additionally, in order to teach practice courses the faculty must have two-year post-MSW practice experiences. Preferred qualifications may include experience with integrative teaching technologies (e.g., Blackboard, WebCT), experience with social work accreditation process, holding a doctoral degree, and so forth.

Applicants for faculty positions, especially those who have limited or no experiences in higher education may become frustrated because they are turned down after applying to many universities. While the stipulated requirements and qualifications are imperative for selecting the best qualified faculty, they are barriers to a faculty who has just finished the doctoral program and meets some, but not all the qualifications and requirements. Moreover, many stipulated requirements and qualifications discourage potential applicants from 
applying and enrolling in the doctoral programs and influence their decisions indirectly or directly. Many administrators and faculty in social work graduate programs struggle with these requirements and compete with other schools in hiring educators who hold the required academic credentials (Clark, Moore, Johnson, \& Openshaw, 2011; Zastrow \& Bremner, 2004).

According to the CSWE (2014), by the end of 2013, there were 2,545 enrolled doctoral students. Of this number, 1,348 represented students taking coursework (1,010 full-time and 338 part-time) and 1,197 who had completed coursework ( 825 full-time and 372 part-time). Across the country, there are 71 doctoral programs in social work. Of the 105 HBCUs, only 27 offer doctoral degrees in social work (Clark et al., 2011). As of June 2014, CSWE's Commission on Accreditation (COA) reported a total of 763 social work academic programs in the country: 502 accredited baccalaureate, 233 accredited masters, 12 baccalaureate in candidacy, and 16 master of social work programs in candidacy. Despite enormous growth of social work academic programs in the country, Zastrow and Bremner (2004) state, "there is evidence of a shortage of doctoral-prepared faculty available to teach in baccalaureate and master of social work programs regardless of whether they also possess a professional social work degree" (p. 351). A report to the U.S. Congress by the officials of U.S. Department of Health and Human Services (USDHHS, 2006) also indicated a shortage of social workers and estimated that the country would need 110,000 professional social workers in long term care by 2050 .

\subsection{Efforts to Address Shortage of Social Work Faculty}

There has been a rapid increase in the employment of part-time and adjunct faculty in both undergraduate and graduate social work programs as a strategy to address shortage of faculty (Clark et al., 2011; Zastrow \& Bremner, 2004). With many schools of social work facing serious funding cuts, programs, administrators are pressured to make critical decisions relating to financial resources and operational costs. They are pressured and encouraged to do more with less, to be creative in looking for resources, to cut budgets for hiring part-time, adjunct, and visiting faculty to teach courses by offering less money than that paid to full-time faculty, who are in short supply. Similarly, using a national sample, Anastas (2006) found inadequate number of doctoral graduates in social work programs to meet the demand for social work positions. These findings are consistent with those of previous researchers (Bowie \& Hancock, 2000; Karger \& Stoesz, 2003).

\subsection{The Purpose of the Study}

The purpose of this qualitative study is to explore students' perspectives on factors influencing doctoral enrollment in social work program in a HBCU and to develop strategies to boost such enrollment.

\section{Method}

\subsection{Participants}

A convenience sample of nine students was recruited and two separate focus groups were conducted to accommodate students' schedule. The first focus group had seven students and the second had two students. Data were gathered from these two focus studies which involved in-depth interviews with students. During interviews, a semi-structured in-depth interview guide was used, which allowed for exploring consistent themes among participants as well as having enough flexibility to probe for emergent themes. The interviews were held in the conference room of the School with doors closed. Researchers were all present in the data collection process in Fall Semester of 2015, and they all had extensive training in qualitative methods.

All the participants were informed of the purpose of the study, and they all gave written consent to have their conversations recorded and transcribed. Participants were all aware that their names and personal information will not be used in the report and data will be reported in an aggregate form only. The confidentiality and anonymity of their participation were fully guaranteed. This study was approved by the Institutional Review Board at the University.

\subsection{Analysis Plan}

The data analysis had multiple components. Descriptive statistics of the participants was presented. Then, researchers recorded the focus group discussions and carefully transcribed them. Content analysis of transcribed text and interview notes were based on grounded theory (Corbin \& Strauss, 1990), and performed using QSR NVivo 8.0, one of the most widely used software for qualitative study.

The transcripts were repeatedly read by researchers to identify codes, categories, and themes related to the purpose of the study. Several steps were involved to ensure the quality of work. First, the transcribed text was divided into meaningful units that included words, phrases, sentences or paragraphs relevant in content. Then, categories were created to represent groups of meaningful units. Lastly, underlying emerged themes across the 
categories were identified. Undoubtedly, some quotas and important remarks from the participants were incorporated in this study.

\section{Results}

\subsection{Demographic Characteristics}

Table 1 presents the demographic characteristics of nine students from the two focus group interviews. All the participants were African American students. Out of total, seven students were female and two were male. The age distribution of the students indicates that non-traditional (old) students exceeded traditional students (young) in this sample: $11.11 \%$ aged in $20-29,44.44 \%$ in $30-39,33.33 \%$ in $40-49$, and $11.11 \%$ over 50 years old. One fourth of students enrolled in the Advanced Standing MSW program (22.22\%), another one fourth $(22.22 \%)$ in the regular two-year MSW program, and one half (55.55\%) in the extended three-year MSW program. The majority of participants had Baccalaureate of Social Work (BSW) degrees (77.77\%). Half of them were employed (44.44\%) and another half unemployed (55.55\%). Less than one third of them had working experience fewer than ten years $(22.22 \%)$, one third worked more than ten years $(33.33 \%)$, and more than one third $(44.44 \%)$ worked over twenty years.

Table 1. Demographic background of interviewees

\begin{tabular}{|c|c|c|}
\hline Variable list & $\mathrm{N}$ & Mean $(\%)$ \\
\hline \multicolumn{3}{|l|}{ Gender } \\
\hline Female & 7 & 77.77 \\
\hline Male & 2 & 22.22 \\
\hline \multicolumn{3}{|l|}{ Age } \\
\hline $20-29$ & 1 & 11.11 \\
\hline $30-39$ & 4 & 44.44 \\
\hline $40-49$ & 3 & 33.33 \\
\hline $50+$ & 1 & 11.11 \\
\hline \multicolumn{3}{|l|}{ Current Education } \\
\hline Advanced Standing MSW program & 2 & 22.22 \\
\hline 2-Year MSW Program & 2 & 22.22 \\
\hline 3-Year MSW Program & 5 & 55.55 \\
\hline \multicolumn{3}{|l|}{ Undergraduate Degree } \\
\hline Social Work & 7 & 77.77 \\
\hline Other & 2 & 22.22 \\
\hline \multicolumn{3}{|l|}{ Employment } \\
\hline Full-time & 3 & 33.33 \\
\hline Part-time & 1 & 11.11 \\
\hline Unemployed & 5 & 55.55 \\
\hline \multicolumn{3}{|l|}{ Length of Working Experience (years ) } \\
\hline Less than 10 & 2 & 22.22 \\
\hline $10-19$ & 3 & 33.33 \\
\hline $20+$ & 4 & 44.44 \\
\hline
\end{tabular}




\subsection{Knowledge about Enrolling in the Doctoral Program}

Participants were asked to recall what they knew about enrolling the doctoral program. Based on own experience, experience with friends and family, and all of them expressed their thoughts and concerns about the doctoral program. Their discussions covered a wide range of topics such as writing skills, curriculum structure, technology in the classroom, funding, scholarship, family-school balance, employment outlook, financial costs, research and scholarship, and accommodations for non-traditional students. All these barriers prevented them from moving into the doctoral program.

Participants frequently expressed their concern about writing a research paper following the style of American Psychological Association (APA). All of them agreed that more instructional hours in writing preparation will enhance their writing competency, and they desired to become effective writers. As they expressed:

It is related to academic expectations... Writing is not a struggle for me but it is a problem for a lot of students. APA should not be something that students get stuck... We need to teach students new APA manual... I will be afraid of some higher caliber. If I lose, I will be afraid... In terms of APA, no one used APA style when I was in school 25 years ago. I am panelized by not having gone to the school for twenty-five years.

The curriculum structure was another area of concern. As one students said, "Certain classes should be taught first. Reordering the classes may help students".

Technology in the classroom was well stated. One student responded, "Technology has to be in place". Another student explained, "I want to enroll in the University's doctoral program. But I need more hands-on experience. In my online MSW program, we click in the conference room and we can meet any time. The professor can explain to thirty people in the same time. We no longer stand outside (the office) in long line. That is the technology".

Respondents were cognizant of the importance of research, scholarship and financial resources for their decision to enroll in the doctoral program. One student said, "My concern is the availability of scholarships. Who wants to have high debts?" Another student described the necessity of engaging in scholarly activities, "I want my university to put research and scholarship information online. So that I can know it. Students get flood emails. We received scholarship, but it is up to me to apply". Another student emphasized the financial costs of enrolling in the doctoral program, as said "I have to re-evaluate my options. Where are my opportunities? At some particular point of time, whether benefits will exceed costs?"

Another commonly mentioned theme related to employment prospects. The majority answered along these lines: "What jobs can I do with PhD? This is not a lucrative business. It is not alike doctor of medicine that we know financial security comes with that". "Where is it going to put me for my career professionally? How does it compare to other universities? What makes up with a good doctoral program? Do professors publish? Do they have reputation of publishing? As for me, $\mathrm{PhD}$ is prestige. I am Doctor so on so".

Participants heavily commented on accommodations for non-traditional students. One student said, "The program does not accommodate non-traditional students. I have to stop working. Not everyone can afford to do that. It affects your performance in the program". Another student with similar views said, "This program does not cater for non-traditional students. Most of students who go back to graduate school are 35 or older. Get married and have career". Another echoed and reflected the difficulty to make family-school balance, "Do I have time and energy to do that? How much sacrifice do my family have to stay? How am I going to get through it? I have to make adjustments".

A lot of constructive strategies emerged in order to expand the enrollment. One student spoke of the summer classes, and another spoke of repositioning the program. The following was representative of their views.

Summer classes are needed. Right now, I have to prolong my Master of Social Work program to three years. Look out to see what other schools are doing better. Look at your major competitors and make comparison. How progressive are their programs? What are they doing? Where are their students? What are they not doing?

We are the only accredited program within 200 miles, North or South. There is no way other schools can take advantage of it. If the University, at some point, can shift the gear for non-traditional students, there will be an increase in enrollment because there are so many.

\subsection{Obtaining Information about the Process of Earning a Doctoral Degree}

Given that the majority of participants were non-traditional students, they expressed the lack of individualized guidance among this special student group. They all understood that "the process is difficult", and "it is not going to be easy, and a lot of sleepless nights". "It will be more challenging than Master's program". Learned 
either by themselves or by friends and families, participants knew the various stages of earning a doctoral degree-admissions, financial aid, coursework, candidacy, and dissertation.

Mentorship was the biggest concern. Since students had to make several years' commitment toward the degree completion, they felt scared to fail. Besides the normal mentorship (advisement) from the university, students were more concerned about the day-to-day guidance. As one student answered, "I do not know anybody can help me". Another answered, "I do not know a person who can guide me through dissertation process. Every factor has to be perfect. How can I do that?"

\subsection{Holding Expectations for Earning a Doctoral Degree}

Students understand that getting a $\mathrm{PhD}$ can be both rewarding and challenging, and it involves certain amount of drive. Expectations can be related to personal advancement, as stated "it is kind of personal satisfaction. It will add more accountability. I will never stop learning. I want to teach in a HBCU. I want to become a professional". Expectations can also be related to financial incentives, as described "I can maximize my earning potential. I am not going to put myself in debt and stay in poverty. I want to live comfortably". "I can make more money and own my agency". For some students, expectations can be related to professional development, as reported "I respect professors as authority and experts. Everyone can benefit from having a social work friend". "From clinical perspective, I am able to work with all kinds of clients, counsel people, make referral and diagnosis. Other than direct practice, I can also do administrative work, make policy implications". One student clearly made comments that "with a $\mathrm{PhD}$ degree, I can become front-runner for policy changes. I can better advocate for my clients and make more community-driven initiatives".

\section{Discussion}

The findings suggest that HBCUs can boost the doctoral enrollment by utilizing more effective strategies. With the advancement in smartphone and wireless technology, college is no longer the privilege of full-time young traditional students. As the economy is making structural changes, adults start looking for more education and better skills. As Pelletier (2010) explained, "looking at the demographics of today's student body, nontraditional is the new traditional. How can public universities best serve today's older student population". As the majority of the study participants were non-traditional students, their perspectives on the doctoral enrollment reflected the recent trend. The discussions resulted in identifiable strategies such as more summer courses, more online courses, more flexible class time (weekends/evening hours), more integration of technology in the classroom, and better curriculum structure to attract a more diverse body of applicants.

The declining enrollments in doctoral social work programs has various implications for education, research, and practice in social work. These implications include limited scholarship and research-informed evidence in practice. Another implication relates to reduced scholarly work that focuses on the investigation of psychosocial and behavioral factors contributing to social dysfunction and inadequate service delivery among diverse communities and the aging populations at risk of developing chronic diseases (e.g., Alzheimer, cancer, diabetes, and cardiovascular).

The current project is part of a comprehensive study of increasing doctoral enrollment. Besides conducting focus group study of MSW students, future research will interview doctoral students and faculty members for their thoughtful insights. Researchers will implement a Brown Bag, Mentoring, and Outreach approach (BMO) to recruit participants in this regard.

The Brown Bag Research Forum is a monthly scholarly event for faculty, staff, and students across campus at this University or other institutions, run by research faculty in School of Social Work. The purpose of this forum is to provide a venue where colleagues are able to present ongoing projects and research in a stimulating and collaborating environment. Participants can benefit from interactions between one's own work and that of others, work toward enhancing research productivity, knowledge sharing, cooperation and collaboration as well as reducing the negative effects of isolation of doing research. Normally, the forum takes place during lunch-breaks the last Friday of each month in order to provide opportunities to all voluntary attendees to participate. The food and drink are provided each month. Usually the students are engaged in active communications and discussion of the topic after the research updates.

Brown Bag presentations, mentoring students, and outreach programs can be effective strategies for recruiting potential applicants for doctoral program. The literature has shown that university students, especially African Americans attribute their academic success to three major factors: personal ambition, family support, and faculty support (Brown, 1999; Van Stone et al., 1994). For African American students, enrollment in the doctoral program is impeded by institutional, environmental, and motivational factors. Although these factors may affect 
enrollment among African American potential enrollees differently, they equally play a significant role in the enrollment, persistence, and graduation processes. Therefore, adopting the BMO approach can be used to recruit students aggressively into doctoral program in social work or other academic programs. The BMO approach has a higher likelihood of boosting enrollment by targeting to address those factors that hinder students' willingness and decisions to enroll in the doctoral program. Factors such as lack of motivation, lack of personal and academic self-efficacy, insufficient information about resources, and inadequate use of social support systems effectively (family, peers, faculty, staff) can be addressed through BMO by employing structured, directed, and expressive advisement, mentoring, and outreach activities geared towards boosting student enrollment. Despite its potential usefulness, BMO has not been applied as it should be in higher education, especially in many HBCUs that enroll predominantly African American students. Additionally, there is no, or limited, literature on its influence on student enrollment in social work doctoral programs.

This study had several limitations. One is that researchers were unable to talk with more young traditional students who were enrolled in the MSW program. Because of the convenience sampling, researchers identified participants through words of mouth. A more representative body of respondents will expand the research findings. A second is related to the small sample size. More participants can bring more diverse and dynamic conversations. Despite these limitations, this study provides new and insightful information, and allow educators to look more closely at developing effective programs to boost enrollment.

\section{References}

Advancement of Doctoral Education in Social Work (GADE). (2013). Quality guidelines for PhD programs in social work. GADE Task Force on Quality Guidelines (Approved Aril 2013). Retrieved from http://www.gadephd.org/LinkClick.aspx?fileticket=6RvhDyHRxQA\%3D\&tabid=84\&portalid=0

Anastas, J. W. (2006). Employment opportunities in social work education: A study of jobs for doctoral graduates. Journal of Social Work Education, 42(2), 195-209. https://doi.org/10.5175/JSWE.2006.200400426

Anastas, J. W. (2012). Doctoral education in social work. New York: Oxford University Press. https://doi.org/10.1093/acprof:oso/9780195378061.001.0001

Anastas, J. W., \& Kuerbis, A. N. (2009). Doctoral education in social work: What we know and what we need to know. Social Work, 54(1), 71-81. https://doi.org/10.1093/sw/54.1.71

Bowie, S., \& Hancock, H. (2000). African Americans and graduate social work education: A study of career choice influences and strategies to reverse enrollment decline. Journal of Social Work Education, 36(3), 429-448.

Clarkk, H. G., Moore, B. A., Johnston, L. B., \& Openshaw, L. (2011). Using adjuncts in social work education:

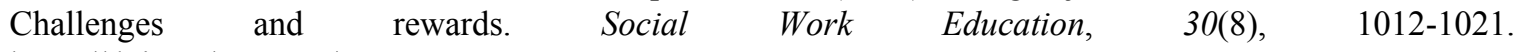
https://doi.org/10.1080/02615479.2010.534450

Corbin, J., \& Strauss, A. (1990). Grounded theory research: Procedures, canons and evaluative criteria. Qualitative Sociology, 13, 3-21. https://doi.org/10.1007/BF00988593

Council on Social Work Education (CSWE). (2010). 2010 Statistics on social work education in the United States: A summary. Alexandria, VA: Council on Social Work Education.

Council on Social Work Education (CSWE). (2012). Handbook of social work accreditation standards and procedures for the 2008 educational policy and accreditation standards (EPAS). Retrieved from http://www.cswe.org/File.aspx?id=64764

Council on Social Work Education (CSWE). (2014). 2013 Annual statistics on social work education in the United States: Alexandria. VA: Council on Social Work Education.

Council on Social Work Education (CSWE). (2014). Accreditation. Retrieved from http://www.cswe.org/Accreditation.aspx

Golde, C. M., \& Walker, G. E. (Eds.). (2006). Envisioning the future of doctoral education: Preparing stewards of the discipline. New York, NY: Jossey-Bass/John Wiley \& Sons.

Karger, H. J., \& Stoesz, D. (2003). The growth of social work education programs, 1985-1999: Its impact on economic and educational factors related to the profession of social work. Journal of Social Work Education, 39(2), 275-295. 
Pelletier, S. G. (2010). Success for Adult Students. Retrieved from http://www.aascu.org/uploadedFiles/AASCU/Content/Root/MediaAndPublications/PublicPurposeMagazine s/Issue/10fall_adultstudents.pdf

Reisch, M., \& Jarman-Rohde, L. (2000). The future of social work education in the United States: Implications for field education. Journal of Social Work Education, 36(2), 201-214.

United States Department of Health and Human Services (USDHHS). (2006). The supply and demand of professional social workers providing long-term care services. In Report to Congress. Washington, D.C.: U.S. Department of Health and Human Services. Retrieved from http://aspe.hhs.gov/daltcp/reports/2006/SWsupply.pdf

Walker, G. E., Golde, C. M., Jones, L., Bueschel, A. C., \& Hutchings, P. (2008). The formation of scholars: Rethinking doctoral education for the twenty-first century. New York, NY: Jossey-Bass/John Wiley \& Sons.

Whitaker, T., Weissmiller, T., \& Clark, E. (2006). Assuring the sufficiency of frontline workforce: A national study of licensed social workers. Washington, D.C.: National Association of Social Workers (NASW).

Zastrow, C., \& Bremner, J. (2004). Social work education responds to the shortage of persons with both a doctorate and a professional social work degree. Journal of Social Work Education, 40(2), 351-358.

\section{Copyrights}

Copyright for this article is retained by the author(s), with first publication rights granted to the journal.

This is an open-access article distributed under the terms and conditions of the Creative Commons Attribution license (http://creativecommons.org/licenses/by/4.0/). 